\title{
Articulações entre Conceitos Fundamentais da Psicanálise, sua Clínica e a Pesquisa na Universidade
}

\author{
Roberto Pires Calazans Matos \\ João Gualberto Teixeira de Carvalho Filho \\ Júlio Eduardo de Castro \\ Maria das Graças Villela Leite Dias \\ Maria Gláucia Pires Calzavara \\ Wilson Camilo Chaves \\ Universidade Federal de São João del Rei
}

\begin{abstract}
RESUMO
O presente artigo pretende estabelecer as coordenadas teórico-clínicas do grupo de pesquisa em psicanálise dentro de uma universidade federal. Apresentamos, por esta razão, os conceitos que são considerados fundamentais para estruturação da teoria e clínica psicanalítica, a maneira pela qual eles podem servir de matriz para pesquisa em diversos temas relevantes para a pesquisa psicanalítica e a sua importância tanto para estabelecer o campo específico da psicanálise quanto a interação dela com outros campos do saber.O artigo termina com a demonstração dos desvios que a psicanálise pode sofrer caso não siga com rigor os conceitos que estruturam sua experiência.
\end{abstract}

Palavras-chave: psicanálise; clínica; pesquisa.

\section{ABSTRACT \\ Articulations Between Fundamental Principles of Psychoanalysis, Psychoanalytical Clinics and Research at a University}

This article intends to establish the theoretical and clinical coordinates of the research group in psychoanalysis at a Federal University. Therefore, we present the concepts which are considered crucial for the structuring of the psychoanalytic theory and clinics - namely, the way they can be the source to research in various important themes to psychoanalytic research, and its importance in establishing the scientific field of psychoanalysis as well as its interaction with other fields of knowledge. The article concludes with the demonstration of the detours that psychoanalysis may face if it does not follow strict concepts which structure its experience.

Keywords: psychoanalysis; clinics; research.

Os conceitos fundamentais da psicanálise - inconsciente, repetição, transferência e pulsão - surgem a partir da clínica freudiana, bem como se consolidam, ou seja, adquirem consistência lógica com o movimento de retorno a Freud promovido por Lacan com vistas à demarcação dos limites da psicanálise e à denúncia dos desvios doutrinal e ético. Chamamos de consistência lógica a formalização operada por Lacan na grade conceitual freudiana que muitas vezes apela para o drama e para o mito para explicação de problemas. Como lembra Antonio Teixeira a propósito da questão do Pai em psicanálise: "O analista Lacan, ao se interessar por essa questão, visaria, antes de tudo, desdramatizar o Pai freudiano pela via de sua formalização, chegando reduzi-lo a uma notação inscrita no lado esquerdo, acima da equação da metáfora paterna, assim como índice de seu produto" (Teixeira, 2006, p. 89).

Por esse aspecto, entendemos a ética da psicanálise como "prática de sua teoria" e a sua teoria como sistematização do que foi inferido a partir da clínica. Daí a relação de indissolubilidade existente entre os conceitos psicanalíticos e a clínica psicanalítica. De modo que, ao nos voltarmos para o estudo dos conceitos fundamentais da psicanálise e seus derivados teóricos, mantemos, com a investigação clínica de fenômenos 
subjetivos variados - por exemplo, as novas formas do sintoma e dos costumes na contemporaneidade um ponto que interroga permanentemente a doutrina.

Temos a necessidade dessa interrogação, devido ao momento atual de nossa disciplina: ela se vê acossada por diversos discursos e problemas que reivindicam cada vez mais a necessidade de uma retomada de nossa orientação. Podemos mencionar, aqui, exemplos extremados desses discursos e problemas. O primeiro exemplo corresponde ao modo de considerar a psicanálise em função de um discurso completamente exterior à sua elaboração teórica e a sua prática, que teria como corolário o evento Estados Gerais da Psicanálise, como lembra Garcia (2004, p. 174). René Major, o principal organizador deste evento, pretende remeter a psicanálise a uma leitura derridiana: "os caminhos desbravados pelas leituras derridianas da obra de Freud e da obra de Lacan transformaram-se em caminhos que a psicanálise seria incapaz de esquecer ou excluir. Se fizesse isso, correria o risco de esquecer a si própria" (Major, 2002, p. 14). Deste modo, vemos a introdução de problemas que não remetem a problemas necessariamente psicanalíticos, mas sociológicos, como podemos ver em textos sobre envelhecimento, filhos de casais separados, etc... Esses autores passam a tomar esses eventos como causa do sujeito, o que em psicanálise é justamente esquecer a dimensão do mesmo.

No segundo exemplo há os autores que pretendem, do interior da própria clínica, pensar em novos modos de intervenção, desde que os princípios sejam respeitados. É o caso de Brodski (2004, p. 9), que dedicou um seminário ao problema do ato psicanalítico como sendo o operador primordial na clínica psicanalítica. É o caso também dos três congressos clínicos (Concliabule d'Angers, Conversation de Arcachon e Convention d'Antibes), que partem de casos clínicos e pretendem apresentar novos modos de intervenção na clínica e de consideração à constituição do sujeito.

Como terceiro exemplo, temos a discussão acerca da inserção do psicanalista nos programas de saúde mental, seja na forma ambulatorial - que se reflete nas supervisões e na dimensão do ensino da psicanálise nas universidades - seja na forma de inserção do psicanalista em programas sociais, para onde ele leva a sua escuta e pensa um modo de intervir sem abandonar seus princípios. Aqui entra em jogo o pensamento de um modo de agir, como lembram Sonia Alberti e Ana Cristina Figueiredo em seu livro sobre psicanálise e saúde mental, "numa instituição de assistência à população que exige a presença de uma orientação comprometida com sua teoria, com sua clínica e com sua ética particular" (2006, p. 13-14).

É nesse confronto permanente da teoria por meio da prática e vice-versa, dos conceitos por meio dos fenômenos clínicos e vice-versa que nos situamos como Núcleo de Pesquisa. Para tal, inspiramo-nos no lema de que "nada é mais prático que uma boa teoria", cabendo-nos esclarecer os conceitos elementares desta teoria, a psicanalítica, como modo de circunscrever as pesquisas teóricas promovidas e sustentadas por um núcleo de pesquisa em psicanálise de uma universidade brasileira. Se temos a necessidade de retomar aqui os conceitos fundamentais da psicanálise como princípios que guiam nossas pesquisas, é porque será sobre esses fundamentos que surpresas e novidades poderão advir. Como destaca Jacques-Alain Miller, é necessário se colocar em "relação a uma rotina para podermos isolar as surpresas" (Miller, 2005, p. 201).

Afinal de contas, fazemos nossas as palavras do epistemólogo e geneticista François Jacob: "decidir quando é tempo de explorar de novo um velho território é uma das maiores qualidades de um cientista" (Jacob, 1981, p. 26). Daí a razão de retomarmos, nesse artigo, em primeiro lugar, os conceitos fundamentais da psicanálise, para destacar a importância deles na condução não somente de pesquisas em psicanálise, mas para pensar a condução de um tratamento. E, em segundo lugar, expor três exemplos de maneiras de pensar a psicanálise que se equivocam por não considerarem a importância dos conceitos fundamentais da psicanálise.

Como conseqüência inelutável dessa perspectiva de pesquisa, temos o estabelecimento dos modos de relação da psicanálise com outros campos de saber, com o objetivo de demarcar a especificidade da clínica e dos conceitos psicanalíticos. A referência à ciência é constante no pensamento psicanalítico. É do conhecimento de todos a tentativa de Freud (1900, 1915a, 1929/1996) de fazer da psicanálise uma ciência. Lacan, por sua vez, insiste em afirmar que "o sujeito sobre quem operamos em psicanálise só pode ser o sujeito da ciência" (Lacan, 1965/1998, p. 873), mesmo que esta não seja uma ciência, nem uma filosofia (Lacan, 1980), e menos ainda uma ciência humana (Lacan, 1965/1998). A necessidade de definir com maior precisão a compatibilidade lógica entre os pensamentos psicanalítico e científico se dá em função das seguintes questões: por que afirmar, como faz Lacan (1966/1998) que a psicanálise só pode existir num mundo em que a ciência é possível, mesmo que ela não seja uma ciência? A que região de problemas se 
refere o pensamento psicanalítico? E em que aspectos a psicanálise é compatível com a ciência? Questões que não são meramente acessórias, pois se originam de um debate com outros campos do saber e delimitam a especificidade dos conceitos fundamentais da psicanálise em suas relações com a clínica psicanalítica.

Encontramos essa preocupação presente na definição da psicanálise feita por Freud em 1922 para figurar como um verbete em uma enciclopédia sobre a sexualidade:

A psicanálise é o nome de um procedimento para a investigação de processos mentais que são quase inacessiveis por outro modo; de um método (baseado nessa investigação) para o tratamento de distúrbios neuróticos e de uma coleção de informações psicológicas obtidas ao longo dessas linhas e que gradualmente se acumula numa nova disciplina cientifica. (Freud, 1922/1996, p. 253)

Lacan (1967/2003), ao retomar essa definição em um momento crucial da história da psicanálise - a formação de uma Escola de psicanálise para avaliar os desvios efetuados pelos pós-freudianos e a retomada do sentido do rigor das articulações conceituais freudianas - irá enfatizar a singularidade e a abertura de um novo campo de experiência que a psicanálise traz com seus conceitos fundamentais. Ora, aqui temos articulada a nossa proposta: estudo dos dispositivos clínicos e das elaborações que estes forçam a psicanálise a fazer para se constituir como teoria da clínica.

A teoria psicanalítica da clínica aparece em função do abandono, por Freud, da hipnose e do distanciamento da "teoria da sedução traumática". Foi pela introdução do método de associação livre que Freud pôde cunhar o conceito de inconsciente. Esse método veio em função também de um trabalho teórico sobre a função do fantasma, ou seja, de um questionamento da hipótese de que a etiologia da neurose devesse ser buscada em um trauma ocorrido na infância. $\mathrm{O}$ que pretendemos demonstrar é que não podemos de modo algum, em uma pesquisa psicanalítica, descuidar da abordagem dos conceitos fundamentais, pois será em função das vias que eles traçarão no real que poderemos pensar, tanto a ordem de problemas de pesquisa e extensão pertinentes à psicanálise, quanto a direção do tratamento que se espera de um psicanalista.

Em 1915, Freud escreve uma série de artigos que qualifica de metapsicológicos. Com esses artigos, segundo a nota de rodapé em "Suplemento metapsicológico à teoria dos sonhos", Freud pretendia "escla- recer e levar mais a fundo as suposições teóricas sobre as quais um sistema psicanalítico poderia ser fundado" (Freud, 1915b/1996, p. 229). Os artigos metapsicológicos vêm na seqüência de uma outra série de artigos intitulados "Artigos sobre a técnica" (Freud, 1911-1914/1996) e tem como desdobramento uma série de conferências pronunciadas na Universidade de Viena sob o título "Conferências introdutórias à psicanálise" (Freud, 1916 e 1917/1996). Dessa seqüência, podemos estabelecer uma lógica: partindo de questões sobre a clínica, conceitos tidos como fundamentais são elaborados, possibilitando assim a transmissão dos mesmos e a direção do tratamento efetuada pelo psicanalista. Estabelecemos, então, essa lógica inaugurada por Freud como orientação básica para as pesquisas desenvolvidas em um núcleo de pesquisa em psicanálise de uma universidade brasileira.

Freud, com o termo Metapsicologia, determinou os conceitos fundamentais, bem como demarcou um novo campo de experiência, introduzido tanto pela hipótese do inconsciente (Freud, 1900/1996) como pelo procedimento clínico da associação livre. Esse termo, como nenhum outro em psicanálise, não deve ser entendido de maneira inocente, nem como mera especulação. Em primeiro lugar, o termo metapsicologia é cunhado para diferenciar o modo psicanalítico de pensar e tratar as questões do sujeito do modo da psicologia e da filosofia. Não se trata de psicologia, pois não visa a uma modificação do vivido - cognitivo ou comportamental - de um indivíduo, mas da modificação de uma posição subjetiva da qual esse vivido é mera conseqüência. Por isso, é para-além da psicologia. Mas não se trata também de uma metafísica, nem de uma filosofia, pois não pretende que esse sujeito se arvore em outra realidade com sua unidade específica, nem tampouco da afirmação do sujeito como um ser estritamente consciencial.

Desse modo, encontramos uma inextrincável relação entre a especificidade do pensamento e prática psicanalítica e o aparecimento do primeiro conceito fundamental da psicanálise, a saber, o inconsciente. $\mathrm{O}$ inconsciente é o conceito que traça a especificidade do sujeito da psicanálise. Não que antes de Freud, como demonstra Jacques Lacan em seu seminário sobre "Os quatro conceitos fundamentais da psicanálise" (1964/ 1985), não se tivesse pensado em um inconsciente. Mas a especificidade do inconsciente freudiano - o que levou os outros modos de abordar o problema do sujeito a se horrorizarem com a invenção freudiana foi afirmar que o inconsciente é uma rede de pensamento cuja lógica de organização gera efeitos outros para além da lógica da consciência. 
Não podemos, de modo algum, separar o conceito de inconsciente dos efeitos que sua introdução produziu na história das idéias. Lacan nomeou esse efeito de "subversão do sujeito". A subversão pode ser entendida em vários sentidos. Iremos nos deter aqui em três. O primeiro é a retirada de qualquer posição de autonomia do sujeito. Este, por ser um efeito da identificação, não se constitui como unívoco, mas como dividido. Donde Freud afirmar que o "eu não é senhor em sua própria casa" (Freud, 1923/1996, p. 42). O segundo é o procedimento psicanalítico para pensar e tratar as questões desse sujeito, que não é uma unidade e é afetado por um inconsciente. Esse procedimento não pode ser situado como um projeto de compreensão e muito menos como um projeto de esclarecimento do sujeito. Para um sujeito afetado pela hipótese do inconsciente, faz-se necessário um novo meio de aproximação, denominado por Freud "interpretação" e considerado por Lacan como a tática do psicanalista. Esse novo meio visa às falhas do discurso do sujeito, não para corrigi-las, mas para demarcar o que se introduz nessas falhas e que impede de todo modo o esclarecimento. E o terceiro sentido que podemos evocar aqui é o que sustenta a hipótese do inconsciente na interpretação, concebida como modo de ação do analista. Trata-se, portanto, de um discurso que não pode ser reduzido nem a um discurso filosófico - denominado por Lacan de discurso do mestre - nem a um discurso das ciências humanas - que é bastante próximo do que Lacan chama de discurso universitário. Eis a razão de Lacan, em seu texto intitulado $A$ ciência e a verdade (1965/1998), se preocupar em estabelecer uma série de distinções entre o que é a psicanálise e o que ela não é.

Esses três sentidos da subversão do sujeito não aparecem apenas em função de um único conceito fundamental. Como demonstra Dominique Lecourt (1969), um conceito só tem consistência quando em relação a outros conceitos e em função do sentido de um problema. Se o conceito de inconsciente é o que permite a Freud abrir um campo de atuação e de pensamento novo, esse campo só adquire rigor quando esse conceito é articulado a outros conceitos. Não é gratuito que Freud, "bom epistemólogo que era" (Lacan, 1964/1985, p. 155), irá afirmar, em Um estudo autobiográfico: "A teorias da resistência e do recalque do inconsciente, da significação etiológica da vida sexual e da importância dos acontecimentos infantis são os elementos principais do edifício teórico psicanalítico" (Freud, 1925/1996, p. 25). Ora, Lacan, em seu projeto de retomada do sentido e do rigor da experiência freudiana, irá apontar os desvios em que os pós-freudianos caíram, justo por não se atentarem aos problemas relacionados aos conceitos fundamentais. Em seu seminário sobre Os quatro conceitos fundamentais da psicanálise, Lacan (1964/1985) aponta que seu projeto de retorno se ordenou por um aforismo: o de que o instrumento de operação do analista é a fala e o seu campo de atuação é o campo da linguagem. E segue afirmando que diversos autores pósfreudianos se desviaram da experiência freudiana por não levarem em conta a significação disso, por não considerarem que Freud analisa os sintomas e as outras formações do inconsciente da mesma forma que se analisa uma linguagem. Basta conferir seus textos sobre $A$ interpretação dos sonhos (Freud, 1900/1996), sobre a Psicopatologia da vida quotidiana (Freud, 1901/1996) e sobre os $O$ chiste e suas relações com o inconsciente (Freud, 1906/1996). Lacan, por sustentar que o campo de problemas da psicanálise - o sofrimento de um sujeito afetado por um inconsciente e acossado por um gozo com o qual não consegue se identificar e nem dele se livrar - é o campo da linguagem, irá produzir uma depuração do arcabouço conceitual de Freud e estabelecerá os conceitos fundamentais da psicanálise em quatro: o inconsciente, a repetição, a transferência e a pulsão.

Os pós-freudianos, por se descuidarem disso, acabaram enfatizando, ora fases do desenvolvimento, ora relações de objeto, em que buscavam uma suposta dimensão anterior à linguagem. Lacan, por sua vez, critica os autores que o acusam de intelectualismo, por não considerar a energia libidinal. Sabe-se que Freud trata a libido como uma energia e esses autores criticam Lacan por considerar apenas a linguagem, deixando à margem essa energia. Lacan responde da seguinte maneira:

\begin{abstract}
Quanto a mim, só fiz restituir o que Freud enuncia num artigo de 1915 sobre o recalque [1915c], e em outros nos quais voltou a isso: o afeto é deslocado. Como se poderia julgar esse deslocamento se não fosse pelo fato de o sujeito que se supõe não poder correr senão através da representação? (Lacan, 1974/1993, p. 42)
\end{abstract}

Ora, o deslocamento, junto com a condensação, é um dos mecanismos do funcionamento lógico do inconsciente. Os pós-freudianos, por não terem considerado que o conceito de libido só tem sentido em relação ao conceito de inconsciente estruturado como uma linguagem, se afastaram da experiência propria- 
mente psicanalítica. Podemos dizer o mesmo em relação ao conceito de pulsão, ou seja, somente um sujeito afetado pelo inconsciente estruturado como uma linguagem pode ser acossado por uma pulsão e por sua exigência de satisfação constante. Somente para um sujeito, esse modo de satisfação que traz a pulsão, pode ser causa de um enigma, abrindo assim as vias ao desejo.

Se encontramos esses desvios em que incorreram os pós-freudianos, no que diz respeito aos conceitos fundamentais da psicanálise, o mesmo podemos dizer em relação à clínica. Abandonar os conceitos fundamentais da psicanálise implicou em negligenciar tanto seu campo de problemas quanto suas finalidades clínicas. Desse modo, produziu-se na clínica outros fins que não os da psicanálise. Encontramos um exemplo desses desvios clínicos em $A$ direção do tratamento $e$ os princípios de seu poder (Lacan, 1958/1998), em que Lacan comenta e critica a finalidade da "reeducação emocional", tratamento padrão em voga na psicanálise da época. Essa concepção de tratamento transformou o conceito de transferência, um dos quatro conceitos fundamentais da psicanálise. De acordo com os autores da reeducação emocional, a função da psicanálise é pedagógica e de correção. Ora, quando temos a função de correção, temos uma finalidade pré-determinada que pode levar o analista a incorrer em uma direção que Freud, em suas recomendações, de não se deixar levar pelo furor sanandis. $\mathrm{O}$ furor de curar pode, justamente, impedir que a transferência se instale e a série de repetições advenha para indicar o que é da ordem do desejo.

Se a interpretação foi considerada por Lacan como a tática do psicanalista, a transferência foi situada como a estratégia da psicanálise. Pois se a primeira permite ao analista a decifração do sintoma em sua vertente significante, a estratégia é o lugar que servirá de esteio para a construção do fantasma. Como aponta Eric Laurent:

O analista, que introduz no começo da análise a associação livre, o jogo do significante, a liberdade do sonho, encarrega-se do fantasma e até se determina por ela - no sentido mais forte, no sentido em que dizemos que uma variável é determinada. Por isso o analista deve saber para onde está indo; não basta que seja entorpecido pelo fantasma, que é o desenvolvimento da neurose de transferência; ele deve saber para onde está indo e essa é a sua política. (Laurent, 1995, p. 17)
Política decorrente dos efeitos que um tratamento psicanalítico ocasiona: a presença tanto do objeto como impossível quanto da satisfação, propiciando assim respectivamente, a subversão do sujeito e a impotência da significação. Essa distinção entre a dimensão significante e a dimensão do objeto (e da satisfação) encontra-se encarnada em outro conceito fundamental da psicanálise: a repetição. É sabido que Freud não o considerava um conceito fundamental da psicanálise e que, em diversos momentos de sua obra, o reduziu a um efeito da transferência, como fez no texto Recordar, repetir e elaborar (Freud, 1914/1996). Mas também é sabido que é em torno do conceito de repetição que Freud, a partir do que podemos chamar de sonhos traumáticos, tal como desenvolve em Psicanálise e as neuroses de guerra (1919/1996) e em Além do princípio do prazer (1920/1996), irá fazer uma reestruturação de sua obra, passando de sua primeira tópica - inconsciente, pré-consciente e consciente (Freud, 1900/1996) - para a segunda tópica - eu, isso e super-eu - "O eu e o isso" (Freud, 1923/1996). Foi a partir dessa reestruturação que Freud pôde pensar o eu como dividido no processo de defesa (Ichspaltung) devido à insistência de uma satisfação outra, denominada por Freud 'pulsão de morte'. Como o conceito de repetição pôde ser tantas vezes confundido? Podemos arriscar uma resposta parcial a partir da questão da tradução. Se na língua portuguesa podemos denominar os dois eventos (os sonhos traumáticos e a repetição na transferência) com o nome de repetição, em alemão há duas palavras distintas: agieren e wiederholung. O primeiro é um fenômeno de transferência em sua dimensão de resistência; o segundo é um conceito que estrutura fenômenos de outra ordem, a saber, a insistência de uma satisfação que não traz nada de prazeroso. Freud aponta essa questão tanto no pensamento sobre os sonhos traumáticos e neuroses de guerra quanto nas brincadeiras infantis (1920/1996). Essas repetições colocam o princípio do prazer em questão, apontando para uma dimensão mais fundamental, levando Freud a re-estruturar sua teoria do aparto psíquico para poder comportar uma dimensão não-representacional (ou não significante, para utilizarmos uma terminologia lacaniana). Foi por esse conceito ter possibilitado a Freud uma reestruturação de sua teoria e, conseqüentemente, da clínica psicanalítica, que Lacan passou a considerá-lo como fundamental. Afinal de contas, como não considerá-lo como fundamental se é em torno dele que podemos diferenciar o sintoma das outras formações do inconsciente? E como não considerá-lo como fundamental se é em 
torno dele que as questões de satisfação para-além do prazer se fazem presentes na clínica?

Qual a importância dessas considerações? Hoje, encontramo-nos em uma posição bastante peculiar em relação à psicanálise: é constante a afirmação de que a psicanálise está em crise, que está sendo ultrapassada ou mesmo reduzida à neurociência. Encontramos em Monique David-Ménard (2002) um exemplo da posição que pretende estabelecer outro referencial teórico para pensar questões da psicanálise. Essa autora considera-se ao mesmo tempo filósofa e psicanalista - o que mostra certa confusão a propósito da irredutibilidade dos dois discursos - e afirma que os conceitos que são indispensáveis para a elucidação de sua prática psicanalítica são: "pulsão, prazer, desprazer, angústia, repetição e transferência" (David-Ménard 2002, p. 152). Além de ampliar o número de conceitos sem justificar-se, simplesmente se esquece do conceito de inconsciente. Ora, esse esquecimento nada tem de gratuito: esquecendo-se da irredutibilidade dos discursos, ela acaba realmente se afastando da questão psicanalítica - clínica de um sujeito - e não levando em conta que os conceitos considerados fundamentais não podem ser pensados em separado. As conseqüências para uma clínica sem o conceito de inconsciente são danosas, pois, como podemos pensar o conceito de transferência e seu pivô - o "sujeito suposto saber" sem o conceito de inconsciente? Como podemos pensar a repetição e a insistência da pulsão sem esse conceito?

Outros autores pretendem dizer que a psicanálise está em crise. Um neurocientista americano - Mark Solms (2004) - criou a sociedade de neuropsicanálise. Segundo esse "autor", a psicanálise freudiana era um discurso não-científico, e com a neurociência conseguiu-se provar as teses de Freud. Podemos encontrar o mesmo em pesquisas levadas à frente em Stanford, onde pesquisadores (Anderson e Gabrieli, 2004) disseram ter provado a existência neuronal do recalcamento. Pois o recalcamento é definido pelos pesquisadores de Stanford como uma "supressão voluntária da memória", amparada em um mecanismo biológico cerebral. "Voluntário" indica uma aposta na consciência. Ora, o conceito de recalcamento não pode ser colocado em termos de supressão voluntária, mas em termos de insistência, devido ao retorno do recalcado em um sintoma que tem seu modo próprio de satisfação (Freud, 1915c/1996). Esse modo de funcionamento coloca em questão o poder da consciência e da vontade. Em suma, devido ao desconhecimento dos conceitos, esses autores pretendem uma objetivação de algo que não é psicanalítico. Desconhecem que esses conceitos não têm sentido algum sem pensar uma clínica e sem pensá-la referida aos problemas de um sujeito que é constituído no campo da linguagem.

Uma terceira categoria de incidência contemporânea, que pretende reduzir a psicanálise a algo que ela não é, se encontra em curso tanto na França quanto no Brasil. Na França, há uma grande discussão sobre a profissionalização do psicoterapeuta. No Brasil, essa discussão é travada em torno da questão do ato médico - os médicos, que não têm formação e nem conhecimento sobre problemas de sujeito, pretendem ser os orientadores dos psicoterapeutas. Mas pretendem fazer essa avaliação de acordo com a orientação da Organização Mundial de Saúde (OMS), que sugere a implantação de um sistema sindrômico e descritivo de sintomas em lugar de uma clínica da causa, pois desse modo teríamos tratamentos menos onerosos para os cofres públicos. Assim, o DSM-IV se converte em manual da clínica - o que definitivamente não é - e deriva, como prática efetiva, a terapia cognitivocomportamental, em detrimento de qualquer outra forma de tratamento do sofrimento psíquico. Mais uma vez esquecem-se do velho Freud que, em seu texto Sobre o início do tratamento (1912/1996), afirmava que qualquer tentativa de tratar somente dos sintomas acarreta, ao contrário do que pode parecer, um aumento da formação dos mesmos, por não ser colocada em questão a sua causa. Resta então saber se este discurso, que pretende ser zeloso do cofre público, não comporta o desejo de tentar reduzir a psicanálise a um dispositivo disciplinar e evitar, assim, os efeitos da subversão do sujeito.

Se a psicanálise tem sua especificidade, não podemos deixar de lado seus conceitos fundamentais ao tratar questões colocadas hoje, tais como: as novas formas de subjetivação e de gozo, a incidência da extensão da psicanálise às instituições de saúde mental. Aqui trabalhamos tanto com o atendimento psicanalítico ambulatorial no Centro de Atenção Psicossocial da Prefeitura - o que demonstra a viabilidade da psicanálise nesses postos de saúde mental - como trabalhamos o aperfeiçoamento de um dispositivo intitulado Urgência Subjetiva: este dispositivo pretende pensar um modo de trabalhar passagens ao ato não pela via da internação ou medicamentosa, mas possibilitando, já na recepção do caso, uma escuta do sujeito para que ele possa ser encontrar meios de através da fala, já fazer uma primeira nomeação de seu sofrimento. Isto quer dizer que o trabalho de urgência subjetiva como um dispositivo dentro de uma pers- 
pectiva discursiva permita que o sujeito (criança ou adolescente) capte a causa da ruptura que provocou a crise e trabalhe para que o tratamento inaugure um tempo que não seja o da pressa, mas um tempo onde ele possa se interrogar sobre si próprio, através do recurso da palavra, prescindindo das passagens ao ato, que colocam o sujeito em risco.

Se a psicanálise é uma teoria da clínica, e se a clínica, por sua vez, a força a pensar a sua teoria, introduzindo novos problemas e conceitos, não podemos, por outro lado, nos esquecer da orientação traçada por Freud: a clínica é sempre a clínica de um ser falante. Somente assim podemos avaliar se essas novidades trazem realmente impasses à psicanálise ou se são afirmações de outros discursos que pretendem limitar, mais uma vez, o seu alcance.

Desse modo, pretendemos com este núcleo de pesquisas, manter aberto o viés crítico e clínico da psicanálise, afirmando sua irredutibilidade e avaliando seus efeitos sobre a clínica. Com isso, pretendemos avaliar e alertar sobre os desvios da clínica e da teoria psicanalítica e, ao mesmo tempo, pretendemos considerar alguns aspectos da doutrina que não fazem e nem tampouco, por razões de estrutura, formam/culminam conceito. Conservar uma brecha ao a-semântico, ao impossível de dizer e de escrever e, portanto, de ser representado, tem aqui a função de manter aberta, sujeita a revisões, a teoria psicanalítica, evitando-se assim cair em dogmatismos desnecessários e possibilitando a abertura de novas trilhas de investigação.

\section{REFERÊNCIAS}

Alberti, S., \& Figueiredo, A. C. (2006). Psicanálise e saúde mental: Uma aposta. Rio de Janeiro: Companhia de Freud.

Anderson, M., \& Gabrieli, J. (2004). Neural systems underlying the suppression of unwanted memories. Retirado em 16 de março de 2005, de http://new-service.stanford.edu/news/2004/ january $14 /$ memory-114html.

David-Ménard, M. (2002). Psicanálise e filosofia após Lacan (V. Safatle, Trad.) Em V. Safatle (Org.), Um limite tenso: Lacan entre a filosofia e a psicanálise (pp.147-168). São Paulo: Editora Unesp.

Freud, S. (1996). A interpretação dos sonhos (W. Oliveira, Trad.). Em J. Salomão (Org.), Edição standard brasileira das obras completas de Sigmund Freud (Vol. IV-V, pp. 39-700). Rio de Janeiro: Imago. (Trabalho original publicado em 1900)

Freud, S. (1996). Psicopatologia da vida quotidiana (J. Salomão, Trad.). Em J. Salomão (Org.), Edição standard brasileira das obras completas de Sigmund Freud (Vol. VI, pp. 1-340). Rio de Janeiro: Imago. (Trabalho original publicado em 1901)

Freud, S. (1996). O chiste e suas relações com o inconsciente (M. Salomão, Trad.). Em J. Salomão (Org.), Edição standard brasileira das obras completas de Sigmund Freud (Vol. VIII, pp.
1-267). Rio de Janeiro: Imago, 1996. (Trabalho original publicado em 1906)

Freud, S. (1996). Artigos sobre a técnica (J. O. A. Abreu, Trad.). Em J. Salomão (Org.), Edição standard brasileira das obras completas de Sigmund Freud (Vol. XII, pp. 111-221). Rio de Janeiro: Imago, 1996. (Trabalho original publicado em 19111915)

Freud, S. (1996). Sobre o início do tratamento (J. O. A. Abreu, Trad.). Em J. Salomão (Org.), Edição standard brasileira das obras completas de Sigmund Freud (Vol. XII, pp. 164-193). Rio de Janeiro: Imago, 1996. (Trabalho original publicado em 1913)

Freud, S. (1996). Recordar, repetir e elaborar (J. O. A. Abreu, Trad.). Em J. Salomão (Org.), Edição standard brasileira das obras completas de Sigmund Freud (Vol. XII, pp. 193-207). Rio de Janeiro: Imago, 1996. (Trabalho original publicado em 1914)

Freud, S. (1996). Pulsões e seus destinos (J. Salomão, Trad.). Em J. Salomão (Org.), Edição standard brasileira das obras completas de Sigmund Freud (Vol. XIV, pp. 123-144). Rio de Janeiro: Imago, 1996. (Trabalho original publicado em 1915a)

Freud, S. (1996). Suplemento metapsicológico à teoria dos sonhos (J. Salomão, Trad.). Em J. Salomão (Org.), Edição standard brasileira das obras completas de Sigmund Freud (Vol. XIV, pp. 228-251). Rio de Janeiro: Imago, 1996. (Trabalho original publicado em 1915b)

Freud, S. (1996). Recalque (J. Salomão, Trad.). Em J. Salomão (Org.), Edição standard brasileira das obras completas de Sigmund Freud (Vol. XIV, pp. 151-162). Rio de Janeiro: Imago, 1996. (Trabalho original publicado em 1915c)

Freud, S. (1996). Conferências introdutórias sobre a psicanálise I (J. L. Meurer, Trad.). Em J. Salomão (Org.), Edição standard brasileira das obras completas de Sigmund Freud (Vol. XV, p. 21-288). Rio de Janeiro: Imago, 1996. (Trabalho original publicado em 1916-17)

Freud, S. (1996). Conferências introdutórias sobre a psicanálise II (J. L. Meurer, Trad.). Em J. Salomão (Org.), Edição standard brasileira das obras completas de Sigmund Freud (Vol. XVI, pp. 289-554). Rio de Janeiro: Imago, 1996. (Trabalho original publicado em 1917)

Freud, S. (1996). Psicanálise e as neuroses de guerra (E. A. M. Souza, Trad.). Em J. Salomão (Org.), Edição standard brasileira das obras completas de Sigmund Freud (Vol. XVII, pp. 259264). Rio de Janeiro: Imago, 1996. (Trabalho original publicado em 1919)

Freud, S. (1996). Além do princípio do prazer (E. A. M. Souza, Trad.). Em J. Salomão (Org.), Edição standard brasileira das obras completas de Sigmund Freud (Vol. XVIII, pp. 17-88). Rio de Janeiro: Imago, 1996. (Trabalho original publicado em 1920)

Freud, S. (1996). Dois verbetes de enciclopédia (E. A. M. Souza, Trad.). Em J. Salomão (Org.), Edição standard brasileira das obras completas de Sigmund Freud (Vol. XVIII, pp. 253-280). Rio de Janeiro: Imago, 1996. (Trabalho original publicado em 1922)

Freud, S. (1996). O eu e o isso (J. O. A. Abreu, Trad.). Em J. Salomão (Org.), Edição standard brasileira das obras completas de Sigmund Freud (Vol. XIX, pp. 23-76). Rio de Janeiro: Imago, 1996. (Trabalho original publicado em 1923) 
Freud, S. (1996). Um estudo autobiográfico (C. M. Oiticica, Trad.). Em J. Salomão (Org.), Edição standard brasileira das obras completas de Sigmund Freud (Vol. XX, pp. 17-88). Rio de Janeiro: Imago, 1996. (Trabalho original publicado em 1925)

Freud, S. (1996). Mal-estar na civilização (J. O. A. Abreu, Trad.). Em J. Salomão (Org.), Edição standard brasileira das obras completas de Sigmund Freud (Vol. XXI, p. 73-148). Rio de Janeiro: Imago, 1996. (Trabalho original publicado em 1929)

Garcia, C. (2004). Um limite tenso. Em G. Iannini e cols. (Orgs.), O tempo, o objeto e o avesso (pp. 173-182). Belo Horizonte: Autentica.

Lacan, J. (1985). O Seminário, Livro 11: Os quatro conceitos fundamentais da psicanálise (M. D. Magno, Trad.). Rio de Janeiro: J. Zahar, 1985. (Trabalho original publicado em 1964).

Lacan, J. (1993). Televisão (A. Quinet, Trad.). Rio de Janeiro: Zahar. (Trabalho original publicado em 1974)

Lacan, J. (1998). A direção do tratamento e os princípios de seu poder (V. Ribeiro, Trad.). Em J. Lacan, Escritos (pp. 591-652). Rio de Janeiro: Zahar. (Trabalho original publicado em 1958)

Lacan, J. (1998). A ciência e a verdade (V. Ribeiro, Trad.). Em J. Lacan, Escritos (pp.869-892). Rio de Janeiro: Zahar. (Trabalho original publicado em 1965)
Lacan, J. (1998). Do sujeito enfim em questão (V. Ribeiro, Trad.). Em J. Lacan, Escritos (pp.229-237). Rio de Janeiro: Zahar. (Trabalho original publicado em 1966).

Lacan, J. (2003). O engano do sujeito suposto saber (V. Ribeiro, Trad.). Em J. Lacan, Outros escritos (pp. 329-340). Rio de Janeiro: Zahar. (Trabalho original publicado em 1967)

Lacan, J. (1980). Monsieur A. Ornicar, Verão, 5-8.

Laurent, E. (1995). Versões da clínica psicanalítica (V. Ribeiro, Trad.). Rio de Janeiro: Zahar.

Lecourt, D. (1969). L'épistemologie historique de Gaston Bachelard. Paris: J. Vrin.

Major, R. (2002). Lacan com Derrida (F. Abreu, Trad.). Rio de Janeiro: Civilização Brasileira.

Miller, J. A. (2005). Psicosis ordinária (S. Lauro, Trad.). Buenos Aires: Paidós.

Solms, M. (2004). Freud está de volta. Scientific American Brasil, 3, 17-19.

Teixeira, A. (2007). O nó ateu: Do mito do pai ao pai como sinthome. Curinga, 1, 89-94.

\section{Sobre os autores:}

Recebido: 06/05/2007

Última revisão: 04/04/2008

Aceite final: 10/05/2008

Roberto Pires Calazans Matos: Doutor em Teoria Psicanalítica pela Universidade Federal do Rio de Janeiro. Professor Adjunto do Departamento de Psicologia da Universidade Federal de São João del Rei.

João Gualberto Teixeira de Carvalho Filho: Especialista em Psicologia Clínica pela Pontifícia Universidade Católica de Minas Gerais. Professor do Departamento de Psicologia da Universidade Federal de São João del Rei.

Júlio Eduardo de Castro: Doutor em Teoria Psicanalítica pela Universidade Federal do Rio de Janeiro. Professor Adjunto do Departamento de Psicologia da Universidade Federal de São João del Rei.

Maria das Graças Villela Leite Dias: Doutora em Teoria Psicanalítica pela Universidade Federal do Rio de Janeiro. Professora Adjunto do Departamento de Psicologia da Universidade Federal de São João del Rei.

Maria Gláucia Pires Calzavara: Mestre em Psicologia pela Universidade Federal de Minas Gerais. Professora Assistente do Departamento de Psicologia da Universidade Federal de São João del Rei.

Wilson Camilo Chaves: Doutor em Filosofia pela Universidade Federal de São Carlos. Professor Adjunto do Departamento de Psicologia da Universidade Federal de São João del Rei.

Endereço para correspondência: Roberto Pires Calazans Matos: Praça Dom Helvécio, 74 - 36310-160 São João del Rei - MG. Endereço eletrônico: robertocalazans@ig.com.br. 